\title{
Pooled analysis of two studies evaluating efficacy and safety of olopatadine hydrochloride $0.77 \%$ in patients with allergic conjunctivitis
}

This article was published in the following Dove Press journal:

Clinical Ophthalmology

8 June 2017

Number of times this article has been viewed

Eugene McLaurin'

Mark Bergmann²

Abhijit Narvekar ${ }^{3}$

Adeniyi Adewale ${ }^{3}$

Paul Gomes ${ }^{4}$

Gail Torkildsen ${ }^{5}$

'Department of Ophthalmology, Total Eye Care, PA, Memphis, TN, ${ }^{2}$ Department of Ophthalmology, Apex Eye, Cincinnati, OH, ${ }^{3}$ Department of Ophthalmology, Alcon Research Ltd, Fort Worth, TX, ${ }^{4}$ Department of Ophthalmology, Ora Inc., ${ }^{5}$ Department of Ophthalmology, Andover Eye Associates, Andover, MA, USA
Correspondence: Eugene McLaurin Department of Ophthalmology, Total Eye Care, PA, 6060 Primacy Parkway, Memphis, TN 38119, USA

$\mathrm{Tel}+190176 \mid 1620$

$\mathrm{Fax}+\mid$ 90I 76I 4662

Email emclaurin6@aol.com
Purpose: Two individual phase 3 conjunctival allergen challenge (CAC) studies of similar design have assessed the efficacy and safety of olopatadine hydrochloride ( $\mathrm{HCl}) 0.77 \%$ for the treatment of allergic conjunctivitis. The purpose of this study is to evaluate the integrated efficacy and safety of olopatadine $\mathrm{HCl} 0.77 \%$ from a larger dataset by pooling data from the two individual CAC studies.

Methods: Data were pooled from two phase 3, randomized, multicenter, double-masked, active- and vehicle-controlled CAC studies. The primary comparison was on ocular itching scores between olopatadine $\mathrm{HCl} 0.77 \%$ versus vehicle (at onset and 24 hours) and olopatadine $\mathrm{HCl} 0.77 \%$ versus olopatadine $0.2 \%$ (at 24 hours). Additional end points included conjunctival redness, total redness, and proportion of itching responders at onset and 24-hour duration of CAC. For both primary and secondary analysis, mixed model repeated measures analysis was used, except for proportion of ocular itching responders. Sensitivity analyses were carried out using a two-sample $t$-test.

Results: This analysis included 448 patients. Olopatadine $\mathrm{HCl} 0.77 \%$ was superior to vehicle $(P<0.0001)$ at onset and 24-hour duration of action (difference in means: -1.14 to -1.52$)$ and to olopatadine $0.2 \%(P=0.0009)$ at 24 -hour duration of action in relieving ocular itch. Additionally, olopatadine $\mathrm{HCl} 0.77 \%$ substantially reduced conjunctival redness and total redness over vehicle and olopatadine $0.2 \%$ at onset and 24 -hour duration of action. At 24 hours CAC, there were a higher proportion of itching responders with olopatadine $\mathrm{HCl} 0.77 \%$ compared to vehicle or olopatadine $0.2 \%$ (difference in proportion of responders: $43.17 \%, P<0.0001$, and $17.25 \%, P=0.0012$, respectively). No safety concerns were identified.

Conclusion: This analysis confirms the findings from the individual studies. The rapid onset and prolonged duration of action (for 24 hours) of olopatadine $\mathrm{HCl} 0.77 \%$ supports once-daily dosing in the treatment of allergic conjunctivitis.

Keywords: olopatadine, allergic conjunctivitis, conjunctival allergen challenge, ocular itching, conjunctival redness

\section{Introduction}

Allergic conjunctivitis, caused by immunoglobulin E-mediated inflammatory reaction to an allergen, is the most common form of ocular allergy. ${ }^{1,2}$ Several epidemiological reports estimate its prevalence ranging from $15 \%$ to $20 \%$ worldwide, depending on the geographic location and patients' age. ${ }^{3}$ According to the National Health and Nutrition Examination Survey III data, annually, $\sim 40 \%$ of the population in the US has at least one occurrence of ocular symptoms indicative of allergic conjunctivitis, ${ }^{4}$ with the most common being ocular itching, redness, eyelid swelling, chemosis, and tearing. ${ }^{1,2}$ 
Several treatment options with different mechanisms of action are available for the treatment of allergic conjunctivitis. Olopatadine, an antiallergic agent, exhibits its effects through selective antagonism of histamine $\mathrm{H} 1$ receptors, mast cell stabilization, and prevention of histamine-induced inflammatory cytokine production. ${ }^{5-9}$

Olopatadine $\mathrm{HCl}$ ophthalmic solution at concentrations of $0.1 \%$ and $0.2 \%$ (Patanol $^{\circledR}$ and Pataday ${ }^{\circledR}$, respectively; Alcon Research Ltd, Fort Worth, TX, USA) has been approved for the management of allergic conjunctivitis in over 100 countries, including the US and Canada, as twice-daily and once-daily treatments, respectively. Once-daily doses of olopatadine $0.2 \%$ and alcaftadine $0.25 \%$ reduce signs and symptoms of allergic conjunctivitis for no more than 16 hours. ${ }^{1,10,11}$

Despite the efficacy of available formulations of olopatadine and other topical ocular antiallergy treatments, there is a need for products that address the incomplete symptom relief and/or provide longer duration of symptom relief such that it lasts for at least 24 hours between two consecutive doses with once-daily administration.

To ensure symptom relief over a longer duration, we assessed olopatadine administered once daily at a higher strength. This new formulation contains olopatadine $\mathrm{HCl}$ at a concentration of $0.77 \%(7.76 \mathrm{mg} / \mathrm{mL})$, which is equivalent to $0.7 \%$ olopatadine as a free base. ${ }^{12}$ Olopatadine $\mathrm{HCl} 0.77 \%$ was developed with the rationale of expanding the benefits offered by olopatadine $0.2 \%$, particularly superior and long-lasting relief over a period of 24 hours with once-daily dosing, while maintaining its safety and patient comfort.

Two phase 3 studies were conducted using the CAC model to assess the safety and efficacy of olopatadine $\mathrm{HCl} 0.77 \%$ in patients with allergic conjunctivitis. ${ }^{12-15}$ The outcomes of these two studies supported the recent approval (January 30, 2015) of olopatadine $\mathrm{HCl}$ ophthalmic solution $0.77 \%$ (olopatadine $\mathrm{HCl} 0.77 \%$ ) by the FDA for the treatment of ocular itching associated with allergic conjunctivitis. The results from these two CAC studies demonstrated superiority of olopatadine $\mathrm{HCl}$ $0.77 \%$ over vehicle at onset and 24 hours post-dosing and over olopatadine $0.2 \%$ at 24 hours post-dosing for the treatment of ocular itching in patients with allergic conjunctivitis. ${ }^{16-18}$ In the current article, we report the pooled analysis of these two randomized phase 3 studies to evaluate the integrated efficacy and safety findings from a larger dataset.

\section{Methods}

\section{Study design}

Data were pooled from two similarly designed, phase 3, randomized, multicenter, double-masked, active- and vehicle-controlled, parallel-group studies. The studies used the CAC model (Ora-CAC ${ }^{\circledR}$; Ora Inc., Andover, MA, USA), involving instillation of allergen directly into the eye under controlled conditions, for observing acute allergic responses. ${ }^{17,18}$ The trials were primarily designed to assess the efficacy of olopatadine $\mathrm{HCl} 0.77 \%$ compared with vehicle and olopatadine $0.2 \%$ at onset of action and 24-hour duration of action based on ocular itching scores (evaluated at 3,5 , and 7 minutes post-CAC). Details of the study design, inclusion and exclusion criteria, and assessments of the two individual studies have been published. ${ }^{17,18}$

In brief, the designs of both studies were identical, except that one study had an additional efficacy evaluation visit at 16 hours $^{17}$ and the other included olopatadine $0.1 \%$ as an additional active comparator. ${ }^{18}$

In this pooled analysis, only the treatment arms and efficacy evaluation visits common to the studies were included, that is, assessments of olopatadine $\mathrm{HCl} 0.77 \%$, olopatadine $0.2 \%$, and vehicle arms at onset of action and 24-hour duration of action. The studies were conducted in compliance with the ethical principles of the Declaration of Helsinki and Good Clinical Practice, including the archiving of essential documents. The study protocol and consent form were written in accordance with the standards of the International Conference of Harmonization guidelines for Structure and Content of Clinical Study Reports. The studies are registered with ClinialTrials.gov as NCT01479374 and NCT01743027.

\section{Ethics approval and consent to participate}

Before enrolling any patient, an Independent Ethics Committee or Institutional Review Board (Alpha IRB [San Clemente, $\mathrm{CA}]$ ) reviewed and approved the protocol and informed consent form and provided a copy to the site and Alcon. All patients were informed about the study and provided the opportunity to ask questions. Patients, or their legal representatives, read, signed, and dated the consent form before taking part in any study activity.

\section{Patients}

The study eligibility criteria were similar in both studies. ${ }^{17,18}$ Key inclusion criteria were that patients must be aged $\geq 18$ years with a history of seasonal or perennial allergic conjunctivitis for at least 1 year prior to Visit 1 and have had a diagnostic skin test indicative of allergy for seasonal or perennial allergens within 24 months of Visit 1. Patients had to be willing to discontinue wearing contact lenses for $\geq 72$ hours prior to the first study visit and throughout the study.

Enrolled patients had a positive bilateral CAC response to allergen at Visits 1 and 2. At Visit 1, a positive CAC 
response was defined as a score, in each eye, of $\geq 2$ for itching and $\geq 2$ for redness in two of the three vessel beds within 10 minutes of the last titration challenge. At Visit 2, a positive bilateral CAC response was defined as a score, in each eye, of $\geq 2$ for itching and $\geq 2$ for redness in two of the three vessel beds in at least two of the three post-CAC time points. Patients who had participated in any previous clinical trials with olopatadine $\mathrm{HCl}$ solution $0.77 \%$ were excluded from this study.

\section{Study treatment}

In one CAC study, ${ }^{17}$ patients were randomized $(1: 1: 1)$ to receive one drop per eye of olopatadine $\mathrm{HCl} 0.77 \%$, olopatadine $\mathrm{HCl} 0.2 \%$, or vehicle at Visits $3 \mathrm{~A}$ (Day 0), 4A (Day 14 \pm 2 ), and 5 (Day 21 \pm 3 ) prior to CAC and at Visits $3 B$ (24 hours after Visit 3A), 4B (16 hours after Visit 4A), and 5 (27 minutes after treatment instillation).

In the other CAC study, ${ }^{18}$ patients were randomized $(2: 2: 2: 1)$ to receive one drop per eye of olopatadine $\mathrm{HCl}$ $0.77 \%$, olopatadine $\mathrm{HCl} 0.2 \%$, olopatadine $\mathrm{HCl} 0.1 \%$, or vehicle at Visits $3 \mathrm{~A}$ (Day 0) and 4 (Day 14 \pm 2 ) prior to CAC at 27 minutes ( \pm 1 minute) posttreatment.

\section{Study objectives}

The primary hypothesis for this pooled analysis was that olopatadine $\mathrm{HCl} 0.77 \%$ was superior to vehicle at onset of action and 24-hour duration of CAC and to olopatadine $0.2 \%$ at 24 -hour duration of CAC in relieving ocular itching associated with allergic conjunctivitis. Additional end points included conjunctival redness, total redness, and ocular itching responders at onset of action and 24-hour duration of CAC for olopatadine $\mathrm{HCl} 0.77 \%$ compared with vehicle and olopatadine $0.2 \%$.

Secondary analyses included the comparison of ciliary redness, episcleral redness, chemosis, eyelid swelling, and tearing assessed at onset of action and 24-hour post-dosing for olopatadine $\mathrm{HCl} 0.77 \%$ compared with vehicle and olopatadine $0.2 \%$.

\section{Efficacy assessments}

Efficacy assessments included patient-evaluated symptoms and investigator-evaluated signs of allergic conjunctivitis. The symptoms included ocular itching and tearing assessed on a 0-4 scale with 0.5 -unit increments $(0=$ none, $4=$ very severe $)$, and eyelid swelling assessed on a $0-3$ scale with 1 -unit increments $(0=$ none, $3=$ severe $)$. Investigator-evaluated signs included conjunctival redness, ciliary redness, episcleral redness, and chemosis all assessed on a 0-4 scale with 0.5-unit increments $(0=$ none, $4=$ very severe $)$.
Total redness score, ranging from 0 to 12 , was the sum of the conjunctival, ciliary, and episcleral redness scores. Ocular itching and itching responders were assessed at 3, 5 , and 7 minutes post-CAC. Conjunctival redness and total redness were assessed at 7, 15, and 20 minutes post-CAC. An ocular itching responder was defined as a patient with zero itch (a score of 0 on ocular itching for both the eyes) or with a $\geq 2$-unit reduction in ocular itching relative to a baseline CAC score.

\section{Safety assessments}

The safety of olopatadine $\mathrm{HCl} 0.77 \%$ was assessed by monitoring BCVA, slit-lamp examination, IOP, dilated fundus examination, and all TEAEs. All TEAEs were coded to system organ class and preferred terms using the Medical Dictionary for Regulatory Activities version 15.0.

\section{Statistical analysis}

MMRM analysis of variance was used as the primary analysis method for the pooled efficacy analysis. MMRM analysis included the score from each eye as the dependent variable and fixed-effects terms of study, treatment, eye type, time, and treatment-by-treatment interaction. Estimate of the treatment difference at each post-CAC time point, the average treatment difference (over 3, 5, and 7 minutes post-CAC time points) between olopatadine $\mathrm{HCl} 0.77 \%$ versus vehicle and olopatadine $0.2 \%$, and the associated $95 \%$ confidence intervals and $P$-values were obtained from the MMRM model. For each primary and secondary comparison, the criterion for statistical success was significant at 5\% level in majority of the post-CAC time points; that is, for each comparison, significance was required in at least two out of three time points. The same MMRM model was used for all other secondary end points, except proportion of ocular itching responders, where the analysis was based on proportions and used the chi-squared test. Sensitivity analyses were conducted using a two-sample $t$-test for comparing each post-CAC time point.

The efficacy analysis set was the pooled primary efficacy analysis set from each individual study. Both studies used the ITT set as the primary efficacy analysis set. The ITT set and safety analysis set included all randomized patients who received study treatment.

\section{Results}

\section{Patient demographics and baseline characteristics}

A total of 448 patients were included in this pooled analysis. Of these, 164 received olopatadine $\mathrm{HCl} 0.77 \%, 167$ received 


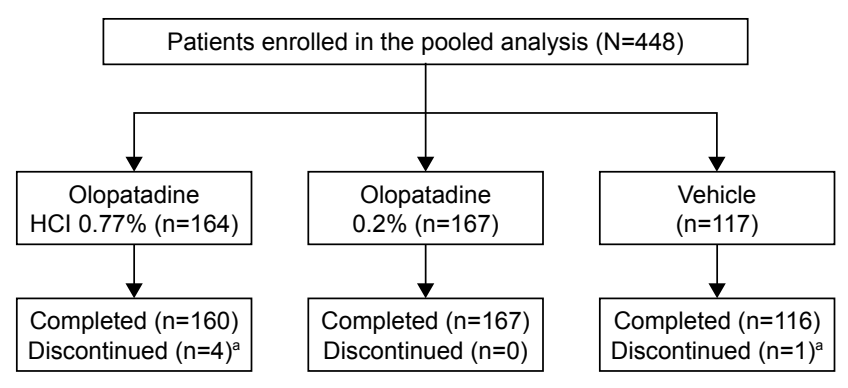

Figure I Patient disposition.

Notes: aDue to adverse events not related to the drug, $\mathrm{n}$ (\%): olopatadine $\mathrm{HCl}$ $0.77 \%, 4$ (2.4); vehicle, I (0.9).

olopatadine $0.2 \%$, and 117 received vehicle (Figure 1). The mean ( \pm standard deviation) age of patients was $40.9( \pm 13.2)$ years, $60 \%$ were females, and $77.5 \%$ were Caucasians. Overall, the patient baseline and demographic characteristics were similar across all treatment groups (Table 1).

\section{Efficacy outcomes}

Analysis of the pooled data demonstrated superiority of olopatadine $\mathrm{HCl} 0.77 \%$ over vehicle $(P<0.0001)$ in relieving ocular itch at all three post-CAC time points

Table I Demographic and baseline characteristics (ITT population)

\begin{tabular}{|c|c|c|c|}
\hline Parameters & $\begin{array}{l}\text { Olopatadine } \mathrm{HCl} \\
0.77 \%(n=164)\end{array}$ & $\begin{array}{l}\text { Olopatadine } \\
0.2 \%(n=167)\end{array}$ & $\begin{array}{l}\text { Vehicle } \\
(n=\mid 17)\end{array}$ \\
\hline \multicolumn{4}{|l|}{ Age (years) } \\
\hline Mean $( \pm S D)$ & $39.7(12.9)$ & $41.3(13.9)$ & $41.7(12.8)$ \\
\hline 18-64, n (\%) & $161(98.2)$ & $159(95.2)$ & I I4 (97.4) \\
\hline$\geq 65, \mathrm{n}(\%)$ & $3(1.8)$ & $8(4.8)$ & $3(2.6)$ \\
\hline \multicolumn{4}{|l|}{ Gender, n (\%) } \\
\hline Male & $60(36.6)$ & $70(4 I .9)$ & $46(39.3)$ \\
\hline Female & $104(63.4)$ & $97(58.1)$ & $71(60.7)$ \\
\hline \multicolumn{4}{|l|}{ Ethnicity, n (\%) } \\
\hline Hispanic or Latino & $26(15.9)$ & $20(12.0)$ & $12(10.3)$ \\
\hline $\begin{array}{l}\text { Not Hispanic or } \\
\text { Latino }\end{array}$ & $137(83.5)$ & $147(88.0)$ & $105(89.7)$ \\
\hline \multicolumn{4}{|l|}{ Race, n (\%) } \\
\hline Caucasian & |3| (79.9) & $124(74.3)$ & $92(78.6)$ \\
\hline African American & $27(16.5)$ & $37(22.2)$ & $17(14.5)$ \\
\hline Asian & $2(1.2)$ & $2(1.2)$ & $3(2.6)$ \\
\hline $\begin{array}{l}\text { American Indian } \\
\text { or Alaska Native }\end{array}$ & $2(1.2)$ & $\mathrm{I}(0.6)$ & $3(2.6)$ \\
\hline Multiracial & I (0.6) & $0(0.0)$ & $0(0.0)$ \\
\hline Other & I (0.6) & $3(1.8)$ & $2(1.7)$ \\
\hline \multicolumn{4}{|l|}{ Allergen, n (\%) } \\
\hline Cat dander & $17(10.4)$ & II (6.6) & $13(11.1)$ \\
\hline Grass & $66(40.2)$ & $74(44.3)$ & $45(38.5)$ \\
\hline Ragweed & $32(19.5)$ & $16(9.6)$ & $27(23.1)$ \\
\hline Trees & $21(12.8)$ & $24(14.4)$ & $10(8.5)$ \\
\hline Dust mites & $24(14.6)$ & $36(21.6)$ & $19(16.2)$ \\
\hline Cockroach & $2(1.2)$ & $2(1.2)$ & $2(1.7)$ \\
\hline Dog dander & $2(1.2)$ & $4(2.4)$ & I (0.9) \\
\hline
\end{tabular}

Note: Olopatadine $\mathrm{HCl} 0.77 \%$ refers to olopatadine $\mathrm{HCl} 0.77 \%$ (equivalent to $0.7 \%$ olopatadine free base) treatment group.

Abbreviations: ITT, intent-to-treat; SD, standard deviation.
$(3,5$, and 7 minutes) at onset of action and 24-hour duration of action $(P<0.0001$ for all; Figure 2$)$. The differences in means were clinically significant $(P<0.0001)$, that is, $>1$ unit at all post-CAC time points at onset of action and 24-hour duration of action. Additionally, at 24 hours, olopatadine $\mathrm{HCl} 0.77 \%$ was superior to olopatadine $0.2 \%(P=0.0009$; Figure 2$)$ in relieving ocular itch at all three post-CAC time points. Overall, olopatadine $\mathrm{HCl} 0.77 \%$ demonstrated a lasting ability to relieve ocular itching for a minimum of 24 hours.

For conjunctival redness, olopatadine $\mathrm{HCl} 0.77 \%$ was superior to vehicle and olopatadine $0.2 \%$ at onset of action and 24 hours post-dosing. The means for conjunctival redness were significantly lower for olopatadine $\mathrm{HCl} 0.77 \%$ versus vehicle at all three post-CAC time points $(7,15$, and 20 minutes $)$ at onset $(P<0.0001)$ and 24 hours $(P=0.0001$; Figure 3). Similarly, olopatadine $\mathrm{HCl} 0.77 \%$ was superior to olopatadine $0.2 \%$ at onset of action $(P<0.0001)$ and 24 hours post-CAC $(P<0.05)$ in relieving conjunctival redness at all three post-CAC time points (Figure 3).

Olopatadine $\mathrm{HCl} 0.77 \%$ was also superior to vehicle and olopatadine $0.2 \%$ in relieving total redness at onset of action and 24 hours post-dosing. The means for total redness were significantly lower for olopatadine $\mathrm{HCl} 0.77 \%$ versus vehicle at all three post-CAC time points at onset and 24 hours (both $P<0.0001$; Figure 4). Similarly, olopatadine $\mathrm{HCl} 0.77 \%$ was superior to olopatadine $0.2 \%$ in relieving total redness at onset of action $(P<0.0001)$ and 24 hours post-dosing ( $P=0.0036$; Figure 4).

The observed proportions of ocular itching responders for olopatadine $\mathrm{HCl} 0.77 \%$, olopatadine $0.2 \%$, and vehicle were $73.2 \%, 69.1 \%$, and $11.1 \%$, respectively, at onset of action and $45.7 \%, 28.5 \%$, and $2.6 \%$, respectively, at 24 hours postdosing. At onset of action, the proportion of ocular itching responders with olopatadine $\mathrm{HCl} 0.77 \%$ was $62.06 \%$ higher than vehicle $(P<0.0001)$ and $4.08 \%$ higher than olopatadine $0.2 \%$ ( $P=0.4142$; Figure 5 ). At 24 hours, the proportion of ocular itching responders with olopatadine $\mathrm{HCl} 0.77 \%$ was $43.17 \%$ higher than vehicle $(P<0.0001)$ and $17.25 \%$ higher compared with olopatadine $0.2 \%(P=0.0012$; Figure 5).

In this pooled analysis, the differences in means for the additional signs and symptoms associated with allergic conjunctivitis favored olopatadine $\mathrm{HCl} 0.77 \%$ over vehicle and olopatadine $0.2 \%$ at onset of action and 24-hour duration of action (Table 2). The differences in means for ciliary redness, episcleral redness, chemosis, eye lid swelling, and tearing between olopatadine $0.77 \%$ and vehicle were significant $(P<0.05)$ at all three post-CAC time points $(7,15$, and 20 minutes; Table 2). 


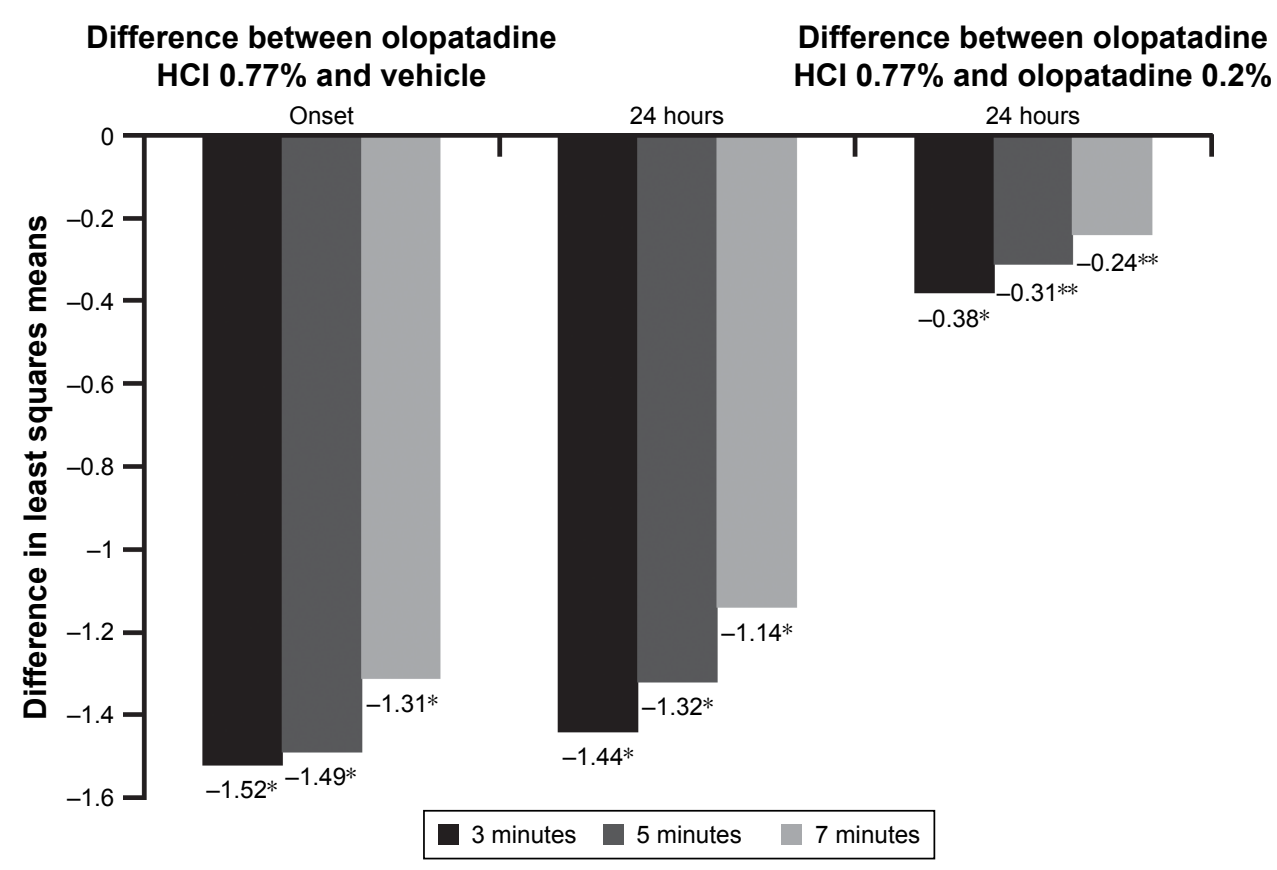

Figure 2 Ocular itching: treatment differences in least squares means at onset and 24 hours post-CAC.

Notes: $* P<0.0001$ overall and at all time points versus vehicle; ${ }^{*} P<0.05$ versus olopatadine $0.2 \%$. The differences in least squares means for ocular itching between olopatadine $0.77 \%$ and vehicle were significant $(P<0.000 \mathrm{I})$ at all three post-CAC time points at onset and 24 hours. The differences in least squares means for ocular itching between olopatadine $0.77 \%$ and olopatadine $0.2 \%$ were significant $(P<0.05)$ at all three post-CAC time points at 24 hours.

Abbreviation: CAC, conjunctival allergen challenge.

\section{Safety}

No clinically relevant differences in safety were noted across the treatment groups in this pooled analysis (Table 3).

A review of AEs did not show any safety concerns with olopatadine $\mathrm{HCl} 0.77 \%$ compared with vehicle and olopatadine $0.2 \%$. Five patients discontinued the study due to TEAEs. Four of these patients had received olopatadine $\mathrm{HCl} 0.77 \%$ (three discontinuations due to viral gastroenteritis and one due to influenza), and one patient received vehicle (discontinuation due to ear infection). None of these TEAEs

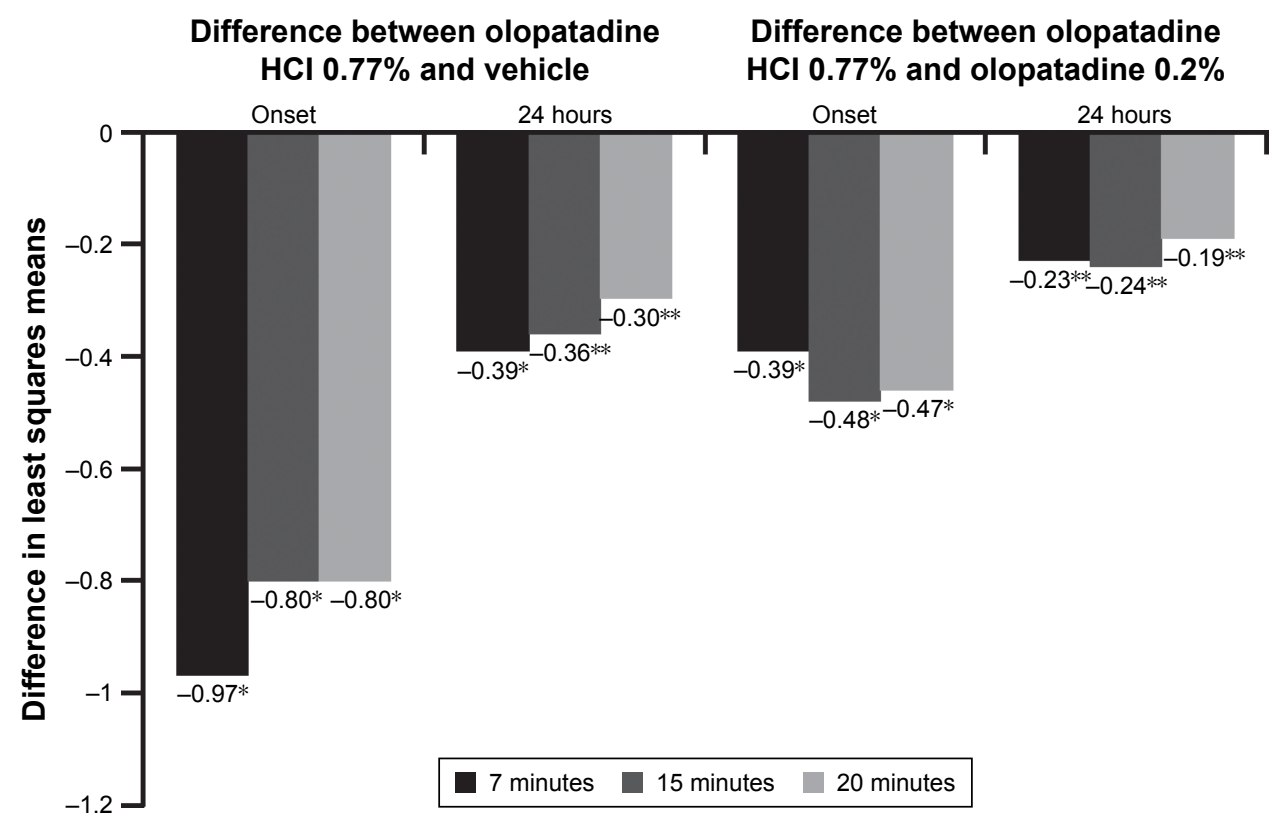

Figure 3 Conjunctival redness: treatment differences in least squares means at onset and 24 hours post-CAC.

Notes: $* P<0.000$ I overall and at all other time points versus vehicle; $* * P<0.05$ overall and at all time points versus olopatadine $0.2 \%$. The differences in least squares means for conjunctival redness between olopatadine $0.77 \%$ and both vehicle and olopatadine $0.2 \%$ were significant $(P<0.05)$ at all three post-CAC time points at 7,15 , and 20 minutes. Abbreviation: CAC, conjunctival allergen challenge. 


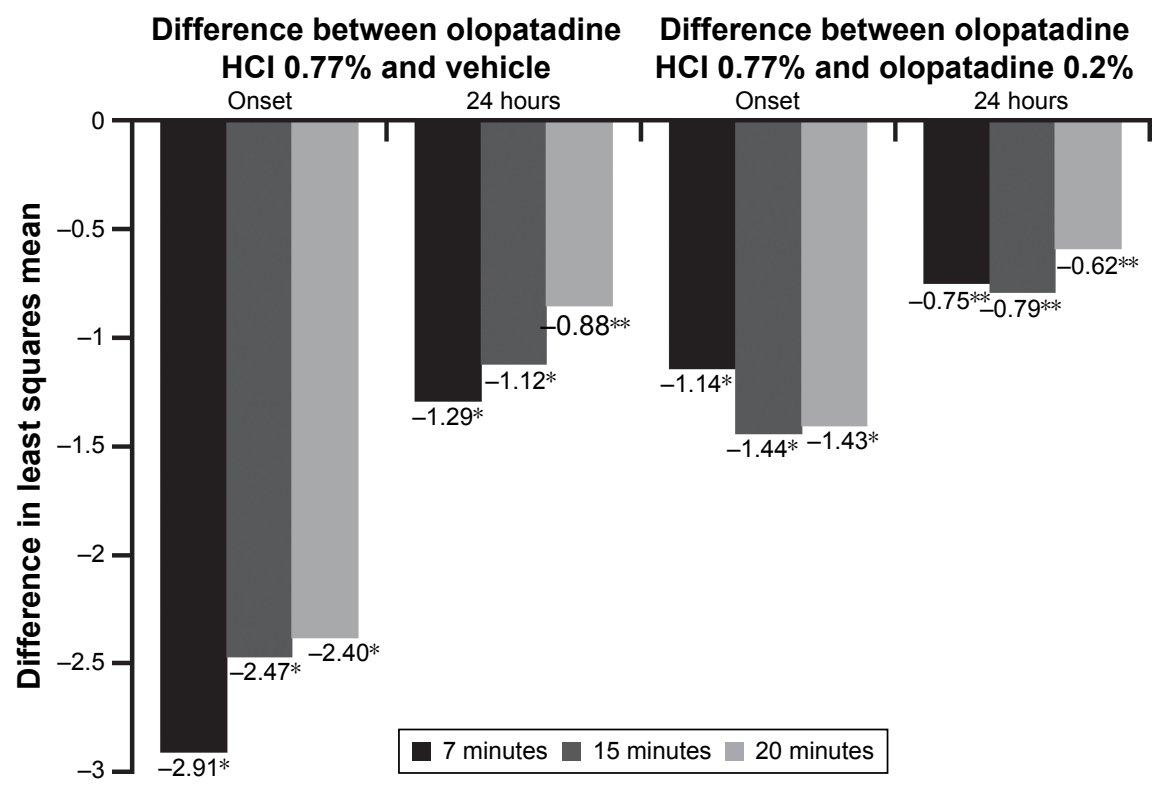

Figure 4 Total redness: treatment differences in least squares means at onset and 24 hours post-CAC.

Notes: $* P<0.000$ I overall and at all other time points versus vehicle; $* * P<0.05$ overall and at all time points versus olopatadine $0.2 \%$. The differences in least squares means for total redness between olopatadine $0.77 \%$ and both vehicle and olopatadine $0.2 \%$ were significant $(P<0.05)$ at all three post-CAC time points at 7 , I5, and 20 minutes. Abbreviation: CAC, conjunctival allergen challenge.

were serious or related to the study treatment. No deaths were reported during the study period. Additionally, no clinically meaningful differences were reported for safety parameters evaluated using BCVA, slit-lamp examination, IOP, or dilated fundus examination.

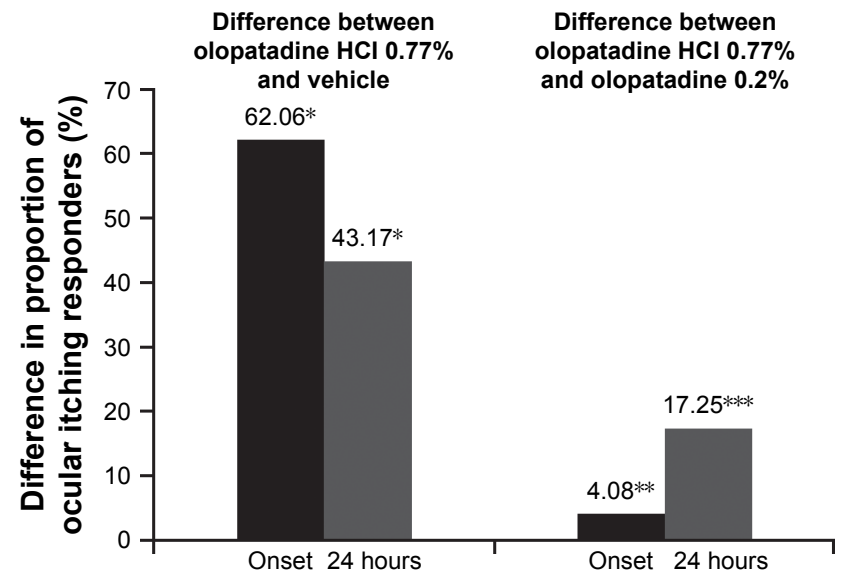

Figure $\mathbf{5}$ Itching responders: treatment differences in proportion of responders at 24 hour duration of action CAC or CAC 24 hours post treatment.

Notes: $* P<0.0001$ overall and at all other time points versus vehicle; $* * P=0.4 \mid 42$ at onset of action; $* * * P=0.0012$ at 24 hours of $C A C$ versus olopatadine $0.2 \%$. The differences in least squares means for proportion of ocular itching responders between olopatadine $0.77 \%$ and vehicle at onset and 24 hours $(P<0.000 I)$ and between olopatadine $0.77 \%$ and olopatadine $0.2 \%$ at 24 hours $(P=0.0012)$ were significant. A responder was defined as a patient with zero itch (a score of 0 on ocular itching for both the eyes) or with at least a 2-unit reduction in ocular itching relative to a baseline score. Two subjects (one in olopatadine $0.77 \%$ group, one in vehicle group) had missing data and were considered as nonresponders in this analysis. Ocular itching score was averaged across both the eyes and over the three post-CAC assessments ( 3,5 , and 7 minutes) for the calculation of unit reduction. Abbreviation: CAC, conjunctival allergen challenge.

\section{Discussion}

In this pooled analysis, olopatadine $\mathrm{HCl} 0.77 \%$ demonstrated superiority over vehicle $(P<0.0001)$ both at onset of action and after 24 hours and over olopatadine $0.2 \%$ at 24 hours in relieving ocular itch. The differences in means for ocular itching between olopatadine $\mathrm{HCl} 0.77 \%$ and vehicle were $>1$ unit at all post-CAC time points. A 1-unit difference compared with vehicle is considered clinically relevant by the FDA.

Prior to the US approval of olopatadine $\mathrm{HCl} 0.77 \%$, the available treatment options for the management of allergic conjunctivitis included dual-acting antihistamines, mast cell stabilizers, and nonpharmacological agents, such as cold compresses or eye lubricants. ${ }^{2,11}$ Olopatadine at a lower concentration of $0.1 \%\left(\mathrm{Patanol}^{\circledR}\right)$, given twice daily, and $0.2 \%$ (Pataday $\left.^{\circledR}\right)$, given once daily, is effective in relieving symptoms associated with allergic conjunctivitis with a good safety profile. ${ }^{12-15}$ The once-daily olopatadine $0.2 \%$, the active comparator in this study, was found to be better than many other available antiallergic treatments in terms of its efficacy and tolerability. ${ }^{1,5,19,20}$ However, none of these medications provided relief over 24 hours from ocular itching; the coverage lasted only for 16 hours post-dosing. ${ }^{17,18}$ Therefore, there is a medical need for a treatment that is effective for at least 24 hours without necessitating a second dose, particularly in patients experiencing moderate-to-severe symptoms or those with incomplete relief from symptoms. Availability 
Table 2 Ocular signs and symptoms: treatment difference in means at onset and 24 hours post-CAC

\begin{tabular}{|c|c|c|c|c|c|c|}
\hline \multirow[t]{2}{*}{$\begin{array}{l}\text { Secondary } \\
\text { endpoints }\end{array}$} & \multicolumn{3}{|c|}{$\begin{array}{l}\text { Difference in means between olopatadine } \mathrm{HCl} \\
0.77 \% \text { versus vehicle and olopatadine } 0.2 \% \text { at } \\
\text { onset of action }\end{array}$} & \multicolumn{3}{|c|}{$\begin{array}{l}\text { Difference in means between olopatadine } \mathrm{HCl} \\
0.77 \% \text { versus vehicle and olopatadine } 0.2 \% \text { at } \\
24 \text {-hour duration of action }\end{array}$} \\
\hline & 7 minutes & I5 minutes & 20 minutes & 7 minutes & 15 minutes & 20 minutes \\
\hline \multicolumn{7}{|l|}{ Ciliary redness $^{\mathrm{a}}$} \\
\hline Vehicle & $-1.01 *$ & $-0.91 *$ & $-0.87^{*}$ & $-0.5 I^{*}$ & $-0.4 I^{*}$ & $-0.30 * *$ \\
\hline Olopatadine $0.2 \%$ & $-0.36^{*}$ & $-0.50 *$ & $-0.49 *$ & $-0.24^{* *}$ & $-0.28^{* *}$ & $-0.21^{* *}$ \\
\hline \multicolumn{7}{|l|}{ Episcleral redness $^{\mathrm{a}}$} \\
\hline Vehicle & $-0.94^{*}$ & $-0.78^{*}$ & $-0.75^{*}$ & $-0.39 *$ & $-0.35 * *$ & $-0.27 * *$ \\
\hline Olopatadine $0.2 \%$ & $-0.38^{*}$ & $-0.46^{*}$ & $-0.47^{*}$ & $-0.26 * *$ & $-0.25 * *$ & $-0.20 * *$ \\
\hline \multicolumn{7}{|l|}{ Chemosis $^{\mathrm{b}}$} \\
\hline Vehicle & $-0.42^{*}$ & $-0.49 *$ & $-0.49 *$ & $-0.36 *$ & $-0.44^{*}$ & $-0.45^{*}$ \\
\hline Olopatadine $0.2 \%$ & -0.06 & $-0.18^{* *}$ & $-0.18^{* *}$ & -0.07 & -0.14 & -0.12 \\
\hline \multicolumn{7}{|l|}{ Eyelid swellingc } \\
\hline Vehicle & $-0.50 *$ & $-0.40^{*}$ & $-0.30^{*}$ & $-0.50^{*}$ & $-0.40 * *$ & $-0.30 * *$ \\
\hline Olopatadine $0.2 \%$ & -0.10 & -0.10 & -0.10 & $-0.20 * *$ & -0.10 & -0.10 \\
\hline \multicolumn{7}{|l|}{ Tearing $^{d}$} \\
\hline Vehicle & $-0.50^{*}$ & $-0.40^{*}$ & $-0.30^{\dagger}$ & $-0.50^{*}$ & $-0.30 * *$ & -0.20 \\
\hline Olopatadine $0.2 \%$ & 0 & -0.10 & -0.10 & -0.10 & -0.10 & -0.10 \\
\hline
\end{tabular}

Notes: a Ciliary and episcleral redness each were assessed on a $0-4$ scale by 0.5 -unit increments: $0=$ none and $4=$ extremely severe; bchemosis was assessed on a $0-4$ scale by 0.5 -unit increments: $0=$ none and $4=$ severe; 'eyelid swelling was assessed on a $0-3$ scale with I-unit increments: $0=$ none and $3=$ severe; and ${ }^{d}$ tearing was assessed on a $0-4$ scale by I-unit increments: $0=$ none and $4=$ very severe. $* P<0.000 \mathrm{I}$ overall and at all other time points versus vehicle; $* * P<0.05$ overall and at all time points versus olopatadine $0.2 \%$

Abbreviation: CAC, conjunctival allergen challenge.

of a once-daily dosing regimen would help maintain efficacy through a full 24-hour period, improve treatment compliance, and reduce exposure to preservatives, which may lower the risk of developing dry eye symptoms in patients with allergic conjunctivitis. ${ }^{19,20}$

The aqueous solubility of olopatadine at neutral $\mathrm{pH}$ is a limiting factor in formulating olopatadine-containing ophthalmic solutions. This new formulation allows olopatadine to remain dissolved in a stable solution at a free base concentration of $0.7 \%$. This improves the concentration of

Table 3 AEs ( $\geq 1 \%$ in any treatment group; safety set)

\begin{tabular}{|c|c|c|c|}
\hline $\begin{array}{l}\text { AE category (MedDRA } \\
\text { PT presented by } \\
\text { SOC), } n(\%) \\
\end{array}$ & $\begin{array}{l}\text { Olopatadine } \\
\text { HCl } 0.77 \% \\
(n=164)\end{array}$ & $\begin{array}{l}\text { Olopatadine } \\
0.2 \%(n=167)\end{array}$ & $\begin{array}{l}\text { Vehicle } \\
(n=I \mid 7)\end{array}$ \\
\hline \multicolumn{4}{|l|}{ Eye disorders } \\
\hline Eye irritation & $2(1.2)$ & 0 & I (0.9) \\
\hline Vision blurred & 0 & $I(0.6)$ & $2(1.7)$ \\
\hline VA reduced & $2(1.2)$ & I $(0.6)$ & 0 \\
\hline \multicolumn{4}{|l|}{ Infections and infestations } \\
\hline Gastroenteritis viral & $3(1.8)$ & 0 & 0 \\
\hline \multicolumn{4}{|l|}{ Nervous system disorders } \\
\hline Dysgeusia & $2(1.2)$ & 0 & 0 \\
\hline \multicolumn{4}{|c|}{ Respiratory, thoracic, and mediastinal disorders } \\
\hline Cough & 0 & 0 & $2(1.7)$ \\
\hline
\end{tabular}

Note: Olopatadine $\mathrm{HCl} 0.77 \%$ refers to olopatadine $\mathrm{HCl} 0.77 \%$ (equivalent to $0.7 \%$ olopatadine free base) treatment group.

Abbreviations: AEs, adverse events; MedDRA, Medical Dictionary for Regulatory Activities; PT, preferred term; SOC, system organ class; VA, visual acuity. drug in the ocular tissue upon instillation $\left(\mathrm{C}_{\max }\right.$ and area under the curve of olopatadine in the conjunctiva), thereby increasing the magnitude of effect and duration of action in the treatment of allergic conjunctivitis. ${ }^{11}$ Olopatadine $\mathrm{HCl} 0.77 \%$ has shown long-lasting efficacy for a minimum of 24 hours post-dose in relieving ocular itch associated with allergic conjunctivitis. When dosed in the morning, this 24-hour duration of efficacy offers a lasting, clinically relevant benefit to patients throughout the day and night. This ensures complete coverage between two consecutive doses of medication administered 24 hours apart.

Results from the supportive pooled efficacy analyses have demonstrated superiority of olopatadine $\mathrm{HCl} 0.77 \%$ over vehicle and olopatadine $0.2 \%$ for the treatment of ocular redness (both conjunctival and total redness) at onset and after 24 hours. These findings are consistent with the outcomes observed in the individual CAC studies. ${ }^{17,18}$ The benefit of a higher concentration of olopatadine was demonstrated by an increase in the proportion of itching responders at 24 hours ( $\sim 17 \%$ greater) compared with olopatadine $0.2 \%$, which was evident because of the 24-hour-lasting efficacy of olopatadine $\mathrm{HCl} 0.77 \%$, unlike olopatadine $0.2 \%$ (16 hours), and the concentration differences. This suggests the beneficial effect of olopatadine $\mathrm{HCl} 0.77 \%$ in providing longer duration of action than olopatadine $0.2 \%$, without losing its potent onset of action. 
In addition, olopatadine $\mathrm{HCl} 0.77 \%$ had lower mean scores compared with vehicle and olopatadine $0.2 \%$ for all other measured signs and symptoms post-CAC at onset of action and 24-hour duration of action. This data support the overall benefit of olopatadine $\mathrm{HCl} 0.77 \%$ over olopatadine $0.2 \%$ in relieving signs and symptoms associated with allergic conjunctivitis, lasting for 24 hours. The similarities in study population and study design justify this pooled analysis, and the consistency of the results across multiple measures supports the overall benefit of olopatadine $\mathrm{HCl} 0.77 \%$ over olopatadine $0.2 \%$ in relieving signs and symptoms associated with allergic conjunctivitis lasting for 24 hours.

No serious AEs were reported with olopatadine $\mathrm{HCl}$ $0.77 \%$ regardless of the treatment duration (onset of action and 24 hours). Overall, the safety profile of olopatadine $\mathrm{HCl}$ $0.77 \%$ was comparable to the vehicle and the well-established safety profile of olopatadine $0.2 \%$.

\section{Conclusion}

This pooled analysis reinforces the findings from the two individual CAC studies demonstrating superiority of olopatadine $\mathrm{HCl} 0.77 \%$ over vehicle and olopatadine $0.2 \%$ for the treatment of allergic conjunctivitis. Olopatadine $\mathrm{HCl} 0.77 \%$ provided superior and longer duration of relief from itching that persisted over a period of 24 hours. No safety concerns were identified with once-daily olopatadine $\mathrm{HCl} 0.77 \%$. The safety profile of olopatadine $\mathrm{HCl} 0.77 \%$ was comparable to that of olopatadine $0.2 \%$. The rapid onset and prolonged duration of action (at least 24 hours) of olopatadine $\mathrm{HCl}$ $0.77 \%$ further support its once-daily dosing in the treatment of allergic conjunctivitis.

\section{Abbreviations}

AEs, adverse events; BCVA, best-corrected visual acuity; CAC, conjunctival allergen challenge; FDA, US Food and Drug Administration; $\mathrm{HCl}$, hydrochloride; IOP, intraocular pressure; ITT, intent-to-treat; MMRM, mixed model repeated measures; TEAEs, treatment-emergent adverse events.

\section{Acknowledgments}

This study was sponsored by Novartis Pharmaceutical Corporation (Fort Worth, TX, USA). Novartis Pharmaceutical Corporation participated in the design of the studies, analysis of the data, and approval of the manuscript. In addition, Ora Inc. provided support with the design and conduct of the studies. Alcon Research sponsored this study. Medical writing and editorial assistance was given by Rhutika
Desai and Usha Gutti (Scientific Services Practice-Product Lifecycle Service, Novartis Healthcare Pvt. Ltd., Hyderabad, India) toward the development of this manuscript.

\section{Disclosure}

Eugene McLaurin has received research grants from the following companies: Aciex, Acucela, Alcon Research Ltd., Allergan, AstraZeneca, Bausch \& Lomb, Inotek Pharma, InSite Vision, Lexicon Pharma, Mimetogen, and Ocular Therapeutix. Mark Bergmann is a study investigator; he has received consultancy fees from Ora, Inc. Abhijit Narvekar was a former employee, and Adeniyi Adewale is an employee of Alcon Research Ltd. Paul Gomes is the vice president of Allergy and an employee at Ora, Inc., an organization that consults and conducts research and clinical trials in the field of ocular allergy and other areas of ophthalmology and allergic diseases. Gail Torkildsen is a study investigator; she has received consultancy fees from Ora, Inc., reimbursement of meeting traveling expenses from Alcon Research Ltd., and research grants from Allergan. The authors report no other conflicts of interest in this work.

\section{References}

1. Abelson MB, Gomes PJ. Olopatadine $0.2 \%$ ophthalmic solution: the first ophthalmic antiallergy agent with once-daily dosing. Expert Opin Drug Metab Toxicol. 2008;4(4):453-461.

2. Sánchez MC, Parra Fernández B, Matheu V, et al. Allergic conjunctivitis. J Investig Allergol Clin Immunol. 2011;21(Suppl 2):1-19.

3. Rosario N, Bielory L. Epidemiology of allergic conjunctivitis. Curr Opin Allergy Clin Immunol. 2011;11:471-476.

4. Singh K, Axelrod S, Bielory L. The epidemiology of ocular and nasal allergy in the United States, 1988-1994. J Allergy Clin Immunol. 2010; 126(4):778.e6-783.e6.

5. Uchio E. Treatment of allergic conjunctivitis with olopatadine hydrochloride eye drops. Clin Ophthalmol. 2008;2(3):525-531.

6. McGill JI. A review of the use of olopatadine in allergic conjunctivitis. Int Ophthalmol. 2004;25(3):171-179.

7. Sharif NA, Xu SX, Miller ST, Gamache DA, Yanni JM. Characterization of the ocular anti-allergic and antihistaminic activity of olopatadine (AL-4943A), a novel drug for treating ocular allergic diseases. J Pharmacol Exp Ther. 1996;278(3):1252-1261.

8. Yanni JM, Stephens DJ, Miller ST, et al. The in vitro and in vivo ocular pharmacology of olopatadine (AL-4943A), an effective anti-allergic/ antihistaminic agent. J Ocul Pharmacol Ther. 1996;12(4):389-400.

9. Yanni JM, Weimer LK, Sharif NA, Xu SX, Gamache DA, Spellman JM. Inhibition of histamine-induced human conjunctival epithelial cell responses by ocular allergy drugs. Arch Ophthalmol. 1999; 117(5):643-647.

10. Greiner JV, Edwards-Swanson K, Ingerman A. Evaluation of alcaftadine $0.25 \%$ ophthalmic solution in acute allergic conjunctivitis at 15 minutes and 16 hours after instillation versus placebo and olopatadine $0.1 \%$. Clin Ophthalmol. 2011;5:87-93.

11. Ackerman S, D’Ambrosio F Jr, Greiner JV, Villanueva L, Ciolino JB, Hollander DA. A multicenter evaluation of the efficacy and duration of action of alcaftadine $0.25 \%$ and olopatadine $0.2 \%$ in the conjunctival allergen challenge model. J Asthma Allergy. 2013;6:43-52. 
12. Iyer GR, Cason MM, Womble SW, Li G, Chastain JE. Ocular pharmacokinetics comparison between $0.2 \%$ olopatadine and $0.77 \%$ olopatadine hydrochloride ophthalmic solutions administered to male New Zealand white rabbits. J Ocul Pharmacol Ther. 2015;31(4): 204-210.

13. Abelson MB, Gomes PJ, Vogelson CT, et al. Clinical efficacy of olopatadine hydrochloride ophthalmic solution $0.2 \%$ compared with placebo in patients with allergic conjunctivitis or rhinoconjunctivitis: a randomized, double-masked environmental study. Clin Ther. 2004;26(8): 1237-1248.

14. Berdy GJ, Spangler DL, Bensch G, Berdy SS, Brusatti RC. A comparison of the relative efficacy and clinical performance of olopatadine hydrochloride $0.1 \%$ ophthalmic solution and ketotifen fumarate $0.025 \%$ ophthalmic solution in the conjunctival antigen challenge model. Clin Ther. 2000;22(7):826-833.

15. Spangler DL, Bensch G, Berdy GJ. Evaluation of the efficacy of olopatadine hydrochloride $0.1 \%$ ophthalmic solution and azelastine hydrochloride $0.05 \%$ ophthalmic solution in the conjunctival allergen challenge model. Clin Ther. 2001;23(8):1272-1280.
16. Vogelson CT, Abelson MB, Pasquine T, et al. Preclinical and clinical antiallergic effect of olopatadine $0.2 \%$ solution 24 hours after topical ocular administration. Allergy Asthma Proc. 2004;25(1):69-75.

17. Torkildsen G, Narvekar A, Bergmann M. Efficacy and safety of olopatadine hydrochloride $0.77 \%$ in patients with allergic conjunctivitis using a conjunctival allergen-challenge model. Clin Ophthalmol. 2015;9:1703-1713.

18. McLaurin E, Narvekar A, Gomes P, Adewale A, Torkildsen G. Phase 3 randomized double-masked study of efficacy and safety of once-daily $0.77 \%$ olopatadine hydrochloride ophthalmic solution in subjects with allergic conjunctivitis using the conjunctival allergen challenge model. Cornea. 2015;34(10):1245-1251.

19. Abelson MB, Chambers WA, Smith LM. Conjunctival allergen challenge: a clinical approach to studying allergic conjunctivitis. Arch Ophthalmol. 1990;108(1):84-88.

20. Mah FS, Rosenwasser LJ, Townsend WD, Greiner JV, Bensch G. Efficacy and comfort of olopatadine $0.2 \%$ versus epinastine $0.05 \%$ ophthalmic solution for treating itching and redness induced by conjunctival allergen challenge. Curr Med Res Opin. 2007;23(6):1445-1452.
Clinical Ophthalmology

\section{Publish your work in this journal}

Clinical Ophthalmology is an international, peer-reviewed journa covering all subspecialties within ophthalmology. Key topics include: Optometry; Visual science; Pharmacology and drug therapy in eye diseases; Basic Sciences; Primary and Secondary eye care; Patien Safety and Quality of Care Improvements. This journal is indexed on

Submit your manuscript here: http://www.dovepress.com/clinical-ophthalmology-journal

\section{Dovepress}

PubMed Central and CAS, and is the official journal of The Society of Clinical Ophthalmology (SCO). The manuscript management system is completely online and includes a very quick and fair peer-review system, which is all easy to use. Visit http://www.dovepress.com/ testimonials.php to read real quotes from published authors. 